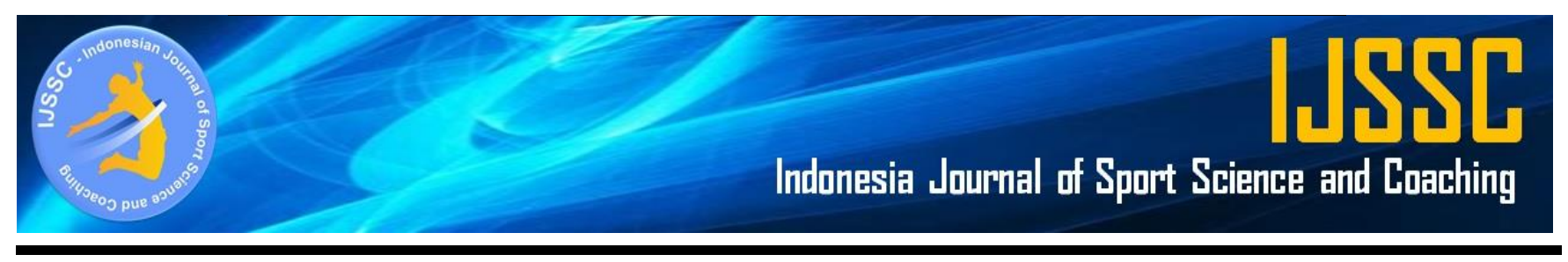

\title{
PENGARUH VARIASI LATIHAN SINGLE LEG JUMP TERHADAP PENINGKATAN HASIL LOMPAT JAUH SISWA SMP ISLAM AL-FALAH KOTA JAMBI
}

\section{The Effect of Variations Single Leg Jump on Long Jump Results in Islamic Junior High School of Al- Falah, Jambi}

\author{
Anggel Hardi Yanto \\ ${ }^{1}$ Program Studi Kepelatihan Olahraga, Universitas Jambi- 36361, Indonesia \\ Correspondence Author: anggelhardiyanto@unja.ac.id Departement of Sport Science and Coaching, \\ Universitas Jambi, Kampus Mendalo, KM 15 Jambi-Ma Bulian Street, Indonesia, 36361
}

\section{ARTICLE INFO}

Article History:

Received : July 20, 2019

Revised form : July 21, 2019

Accepted : August 13, 2019

Published online : August 14, 2019

\section{Keywords:}

keyword 1; Long jump

keyword 2; single leg jump

keyword 3; sport

\section{Kata Kunci:}

kata kunci 1; lompat jauh

kata kunci 2;lompat satu kaki

kata kunci 3; olahraga

\begin{abstract}
ABSTRAK
Tujuan dari penelitian ini adalah untuk mengetahui pengaruh variasi latihan single leg jump terhadap peningkatan hasil lompat jauh siswa SMP ISLAM AL-FALAH Kota Jambi. Penelitian ini menggunakan metode eksperimen, dalam penelitian ini terdapat kelompok eksperimen yang sengaja diberikan perlakuan. Rancangan penelitian ini menggunakan rancangan one group pretest-postest design yaitu kelompok yang diberikan perlakuan, tetapi sebelum perlakuan diberikan terlebih dahulu tes awal (pre test), dan kemudian diakhir perlakuan dilakukan lagi test akhir (post Test). Berdasarkan hasil analisis data pada test awal dan test akhir diperoleh harga t hitung sebesar 8,0633, bila dibandingkan dengan t tabel 1,7531 maka $t$ hitung $>\mathrm{t}$ tabel ini menunjukkan terdapat pengaruh yang berarti. Maka kesimpulan dari hasil penelitian dan perhitungan statistik pada pengujian hipotesis menunjukkan terdapat pengaruh variasi latihan single leg jump terhadap peningkatan lompat jauh siswa SMP Islam Al-Falah Kota Jambi.
\end{abstract}

(C2019 Indonesian Journal of Sport Science and Coaching

\section{ABSTRAK}

The aim of this research is to find the influence of single leg jump to single leg jump result of student at senior high school of Al-Falah Jambi. Experimental method used in this research. Experimental design of this research used one group pre-test and post-test design. As the result of this research pre and posttest have value of $t$-test is 8.0633. This value was compared with t-table (1.7531). The result showed that $t$ value $>t$ table so this research have significant value. Conclusion: Variation of single leg jump have significant result to long jump in Islamic Jounior High School of Al-Falah Jambi.

(C2019 Indonesian Journal of Sport Science and Coaching 


\section{PENDAHULUAN}

Indonesia telah memiliki banyak permasalahan seperti pencemaran lingkungan (Naswir, Arita, Hartati, Septiarini, \& Wibowo, 2019b) yang berdampak pada kesehatan manusia (Naswir, Arita et al., 2019; Wibowo et al., 2019; Wibowo \& Naswir, 2019; Wibowo et al, 2019; Wibowo \& Wiratama, 2017; Wibowo et al., 2018; Winarno et al., 2019). Salah satu upaya yang dapat dilakukan untuk menjaga kesehatan adalah olahraga. Atletik merupakan salah satu cabang olahraga yang bermanfaat bagi kesehatan manusia, cabang olahraga atletik meliputi lari, jalan, lempar, dan lompat, yang telah menjadi aktivitas olahraga tertua dalam peradapan manusia. Atletik merupakan salah satu cabang olahraga yang meliputi lari, lompat, senam, jalan dan lempar, seluruh kegiatan atletik ini akan memberikan dampak baik terhadap kesehatan manusia (Wibowo, 2019; Wibowo \& Indrayana, 2019). Salah satu bentuk olahraga atletik adalah lompat jauh. Lompat merupakan olahraga yang menggabungkan kecepatan (speed), kekuatan (stenght), kelenturan (flexibility), daya tahan (endurance), dan ketepatan (acuration) dalam upaya untuk memperoleh jarak lompatan sejauh-jauhnya.

Perkembangan riset olahraga terus berkembang terutama pada cabang atletik. Penelitian terbaru menintegrasikan antara sains, teknologi dan olahraga untuk memaksimalkan manfaat olahraga bari para pelaku olahraga (Kos, Wei, Tomažič, \& Umek, 2018). Olahraga menjadi salah satu trend dunia di era 2000an sampai saat ini, orang-orang semakin sadar bahwa olahraga tidak hanya sebuah kegiatan biasa, namun bergeser menjadi kebutuhan wajib bagi seluruh manusia.

Olahraga lompat jauh menjadi bagian dari cabang olahraga atletik yang cukup di gemari. Olahraga ini akan melatih kekuatan kaki atlit lompat jauh sehingga tidak hanya menyehatkan namun juga akan memberikan kekuatan kaki yang baik. Penelitian ini akan menjelaskan bagaimana pengaruh latihan single leg jump terhadap efek lompat jauh siswa SMP Al Falah Jambi.

\section{METODOLOGI PENELITIAN}

Penelitian ini menggunakan metode eksperimen, dalam penelitian ini terdapat kelompok eksperimen yang sengaja diberikan perlakuan. Adapun rancangan penelitian ini menggunakan rancangan one group pretestpostest design yaitu kelompok yang diberikan perlakuan, tetapi sebelum perlakuan diberikan terlebih dahulu diberikan tes awal (pre test), dan kemudian diakhir perlakuan dilakukan lagi test akhir (post Test), dimana T1 $=$ Pretest (tes awal), $\mathrm{T} 2=$ Postest (tes akhir), $\mathrm{X}=$ treatment (perlakuan)

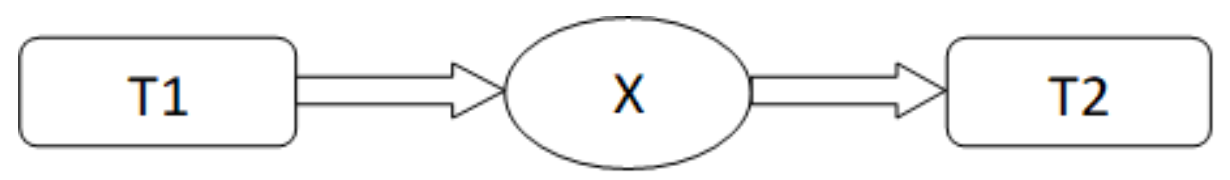

Gambar 1. Metode one group tretest posttest

Penelitian ini dilaksanakan di SMP ISLAM AL-FALAH Kota Jambi pada bulan Agustus 2015. Pengambilan data pre test dan post test dilaksanakan dilapangan SMP ISLAM AL-FALAH Kota Jambi. 
Populasi adalah keseluruhan objek penelitian (Arikunto 2006: 130).Populasi dalam penelitian ini adalah keseluruhan siswa putra kelas VIII SMP ISLAM AL-FALAH Kota Jambi yang berjumlah 15 siswa (Table 1)

Tabel 1. Data Siswa Kelas VIII

\begin{tabular}{cc}
\hline Kelas & Putra \\
\hline VIII 1 & 8 \\
VIII 2 & 7 \\
Jumlah & 15 \\
\hline
\end{tabular}

\section{HASIL DAN PEMBAHASAN}

Data dalam penelitian ini dilakukan tes pada siswa putra SMP ISLAM AL-FALAH Kota Jambi yang menjadi sampel sesuai dengan kebutuhan penelitian.Dimana pada pelaksanaannya tester diberikan 3 kali kesempatan melakukan lompatan, kemudian dari 3 kali lompatan tersebut diambil nilai terjauh untuk dijadikan data. Bentuk pelaksanaannya yaitu tester mengambil ancang-ancang untuk berlari berjarak 30-50 meter, kemudian tester berlari secepat mungkin, pada saat menyentuh tumpuan tester langsung melakukan tolakan sekuat mungkin agar dapat melompat sejauh mungkin. Namun, jika pada saat kaki berada pada papan tolakan, kaki melewati garis akhir papan tolakan maka dinyatakan gagal, dan pada saat mendarat dihitung jejak atau hasil lompatan yang terdekat dari papan tumpuan.Kemudian diukur berapa jauh hasil lompatan menggunakan meteran pada saat pengambilan data. Tes lompat vertikal satu kaki dimulai dari posisi jongkok dalam tunggal dengan jeda. (Gambar )

Tabel 2. Norma Tes Kemampuan Lompat Jauh

\section{Putra}

\begin{tabular}{cccc}
\hline Umur & Memuaskan & Baik & Sangat Baik \\
\hline $11-12$ & $3,1 \mathrm{~m}$ & $3,6 \mathrm{~m}$ & $4,1 \mathrm{~m}$ \\
$13-14$ & $3,6 \mathrm{~m}$ & $4,2 \mathrm{~m}$ & $4,6 \mathrm{~m}$ \\
$15-16$ & $4,2 \mathrm{~m}$ & $4,7 \mathrm{~m}$ & $5,2 \mathrm{~m}$ \\
$17-19$ & $4,6 \mathrm{~m}$ & $5,0 \mathrm{~m}$ & $5,7 \mathrm{~m}$ \\
\hline
\end{tabular}

Analisis data dilakukan untuk menguji hipotesis yang telah dirumuskan.Uji hipotesis yang dipergunakan adalah uji-t.untuk melakukan uji-t populasi harus berdistribusi normal dan bervariansi homogeny, Uji normalitas bertujuan untuk melihat apakah data berdistribusi normal atau tidak, digunakan uji Liliefors, Dilihat dari analisis data dan pengujian hipotesis yang menggunakan rumus uji t-test, dalam penelitian ini diharapkan melahirkan suatu kesimpulan yang dapat sesuai dengan data yang diperoleh. Dengan demikian kesimpulan yang diambil nantinya akan memperlihatkan gambaran langsung dari data yang diharapkan 
selama eksperimen ini dilakukan.Pengetahuan yang diperoleh melalui pendekatan ilmiah dan dibuat berdasarkan teori-teori tertentu secara sistematis dan dilakukan sesuai dengan langkah-langkah atau prosedur yang benar, maka pengetahuan yang didapatkan tentu benar, hingga hasil penelitian dapat diterima kebenarannya.

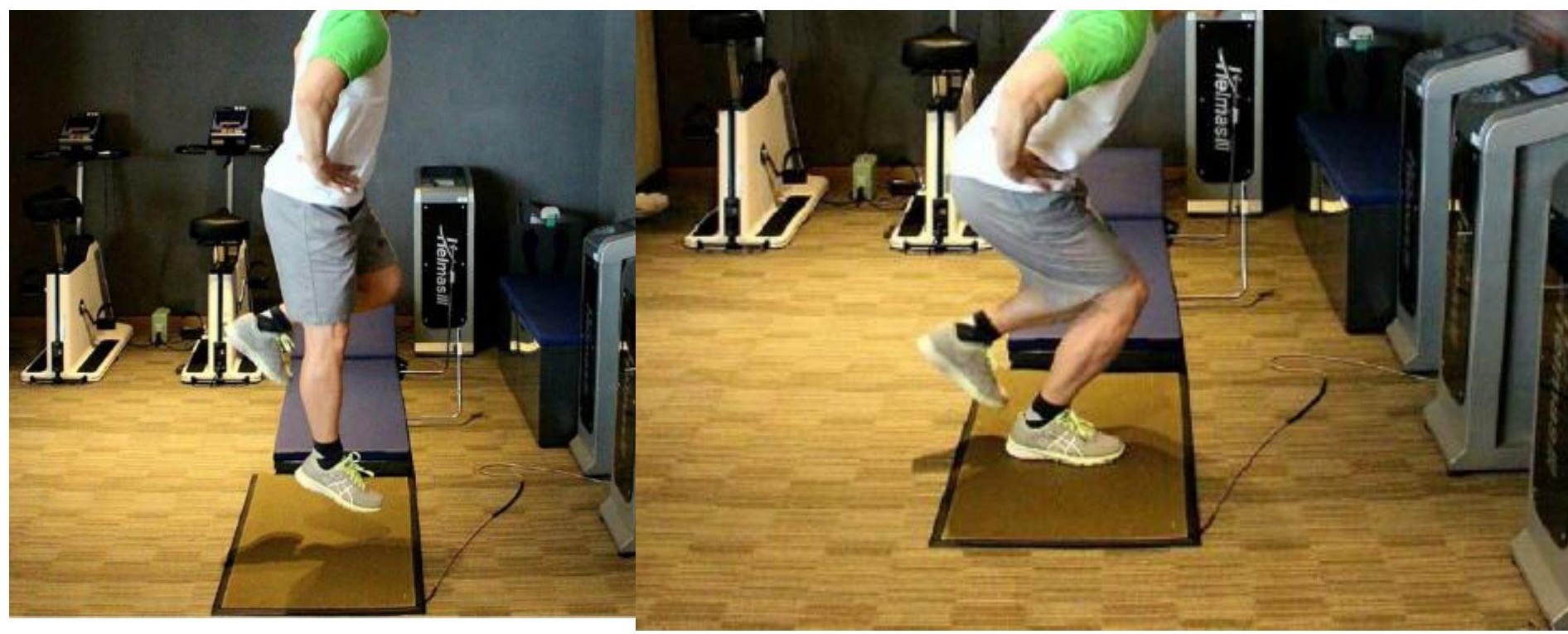

(a)

(b)

Gambar 2. (A) Tes lompat vertikal satu kaki dimulai dari posisi jongkok dalam tunggal dengan jeda. (B) Lompatan vertikal untuk ketinggian maksimum diukur dengan Sar Jump jump analyzer (sistem HELMAS, OnFit, Seoul, Korea) (Won et al., 2018)

Dalam pelaksanaan penelitian ini, test dilakukan sebanyak dua kali yaitu test awal dan test akhir. Test awal dilakukan bertujuan untuk melihat kemampuan awal sampel sebelum eksperimen dan test akhir yang dilakukan bertujuan untuk melihat sejauh mana akibat eksperimen apakah terdapat peningkatan yang berarti. Hal ini dapat dilakukan dengan membandingkan hasil test akhir dan test awal terhadap t tabel dalam taraf signifikasi $5 \%$ dari $(\mathrm{df})=\mathrm{n}-1=14$. Apabila $\mathrm{t}$ hitung $>\mathrm{t}$ tabel ini berarti adanya pengaruh yang berarti dan sebaliknya apabila $t$ hitung $<\mathrm{t}$ tabel ini berarti tidak adanya pengaruh yang berarti. Berdasarkan hasil analisis data pada test awal dan test akhir diperoleh harga $t$ hitung sebesar 8,0633, bila dibandingkan dengan $t$ tabel 1,7531 maka $\mathrm{t}$ hitung $>\mathrm{t}$ tabel ini menunjukkan terdapat pengaruh yang berarti. Dari hasil perhitungan statistik pada pengujian hipotesis menunjukkan terdapat pengaruh variasi latihan single leg jump terhadap peningkatan lompat jauh siswa SMP Islam Al-Falah Kota Jambi.

Lompat satu kaki tidak hanya akan berpengaruh signifikan terhadap kemampuan lompat jauh siswa, penelitian terbaru menyebutkan bahwa latihan lompat satu kaki juga mampu memberikan dampak positif terhadap kemampuan lari siswa (B et al., 2012). Lompat satu kaki juga berpengaruh terhadap kemampuan lompatan pada pemain voli, lompat kodok serta peningkatan daya ledak otot tungkai dan kelincahan (Gambar 2) (Puriana, 2016) 


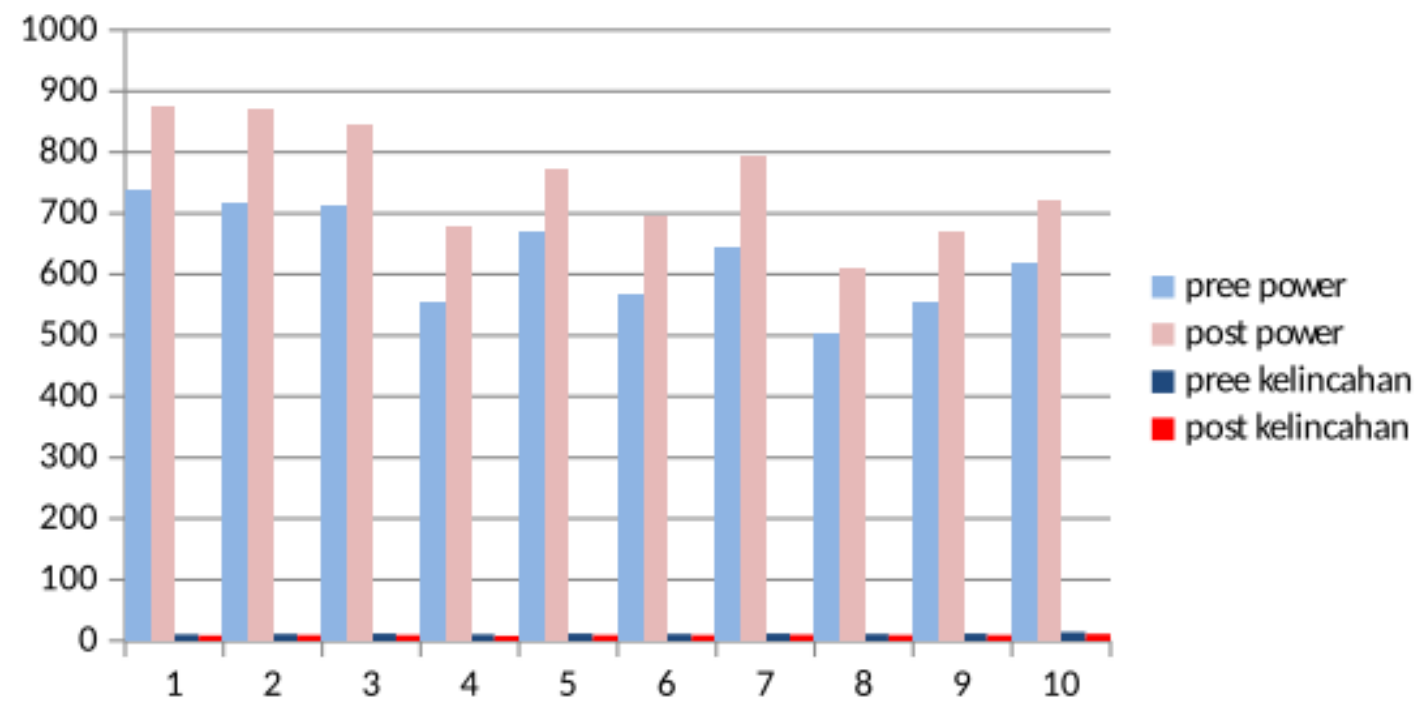

Gambar 3. Analisis pengaruh lompat satu kaki

\section{KESIMPULAN}

Berdasarkan analisis data, diketahui bahwa terdapat pengaruh variasi latihan single leg jump terhadap peningkatan lompat jauh siswa SMP Islam Al-Falah Kota Jambi. dengan hasil uji normalitas yang normal, uji homogeitas yang homogeny dan uji hipotesis yang signifikan untuk taraf nyata $\alpha=0,05$ dengan derajat kebebasan $(\mathrm{d} \cdot \mathrm{b})=(\mathrm{n}-1=14$ diperoleh $\mathrm{t}$ hitung $(8,0633)>\mathrm{t}$ tabel $(1,7531)$.

\section{DAFTAR PUSTAKA}

B, J. C., Waluyo, M., \& Rahayu, S. (2012). Pengaruh Latihan Lompat Kijang Terhadap Kecepatan Lari. Journal of Sport Science and Fitness, 1(1), 1-5.

Kos, A., Wei, Y., Tomažič, S., \& Umek, A. (2018). The role of science and technology in sport The role of science and technology in sport. Procedia Computer Science, 129, 489-495. https://doi.org/10.1016/j.procs.2018.03.029

Naswir, M., Arita, S., Hartati, W., Septiarini, L., \& Wibowo, Y. G. (2019a). Activated Bentonite : Low Cost Adsorbent to Reduce Phosphor in Waste Palm Oil. International Journal of Chemistry, 11(2), 67-76. https://doi.org/10.5539/ijc.v11n2p67

Naswir, M., Arita, S., Hartati, W., Septiarini, L., \& Wibowo, Y. G. (2019b). Utilization of activated bentonite to reduce nitrogen on palm oil mill. International Journal of Chemical Science, 3(4), 89-92.

Puriana, R. H. (2016). Pengaruh pelatihan melompat satu kaki dan melompat dua kaki terhadap peningkatan daya ledak otot tungkai dan kelincahan. Jurnal Buana Pendidikan, 12(22), 69-89.

Wibowo, Y. G. (2019). Managing Sport for Healthy Lifestyle: A Brief Review and Future Research Directions. Indonesian Journal of Sport Science and Coaching, 1(2), 49-57.

Wibowo, Y. G., \& Indrayana, B. (2019). Sport: A Review of Healthy Lifestyle in The World. Indonesian 
Journal of Sport Science and Coaching, 1(1), 30-34.

Wibowo, Y. G., Maryani, A. T., Rosanti, D., Rosarina, D., Program, P., Jambi, U., \& Tangerang, U. M. (2019). Microplastic in Marine Environment and Its Impact. Sainmatika: Jurnal Ilmiah Matermatika Dan Ilmu Pengetahuan Alam, 16(1), 81-87. https://doi.org/10.31851/sainmatika.v16i1.2884

Wibowo, Y. G., \& Naswir, M. (2019). A Review of Biochar as a Low - cost Adsorbent for Acid Mine Drainage Treatment. Prosiding Seminar Nasional Hari Air Dunia 2019, 1-10.

Wibowo, Y. G., Rosarina, D., Fardillah, F., \& Gusva, D. W. (2019). An Overview; Wastewater Treatment Using Biochar to Reduce Heavy Metals. Prosiding Seminar Nasional Hari Air Dunia 2019, 11-16.

Wibowo, Y. G., \& Wiratama, J. (2017). Rancangan Teknis Sistem Penirisan Tambang Pit Donggang Selatan PT Manggala Alam Lestari Kecamatan Bayung Lencir Provinsi Sumatera Selatan. Jurnal Teknik Kebumian, 1(1), 1-8.

Wibowo, Y. G., Zahar, W., \& Maryani, A. T. (2018). Case Study of Pump Planning at PIT Donggang Utara Blok 32 Open Mining, PT Buana Bara Ekapratama. Jurnal Sains Dan Teknologi Lingkungan, 10(2), $115-124$.

Winarno, H., Muhammad, D., Ashyar, R., \& Wibowo, Y. G. (2019). Pemanfaatan Limbah Fly Ash dan Bottom Ash dari PLT SUMSEL-5 Sebagai Bahan Utama Pembuatan Paving Block. Jurnal Teknika, 11(1), 1067-1070.

Won, D., Jin, S., Ik, S., Ho, J., \& Goo, J. (2018). The Knee Single-leg vertical jump test as a functional test after anterior cruciate ligament reconstruction ㄱ. The Knee, 25(6), 1016-1026. https://doi.org/10.1016/j.knee.2018.07.014 